\title{
UV spectrophotometry for monitoring toxic gases
}

\author{
E. Dupuit*, A. Dandrieux, P. Kvapil, J. Ollivier, G. Dusserre and O. Thomas \\ École des Mines d'Alès, 6 avenue de Clavières, 30319 Alès Cedex, France
}

\begin{abstract}
The need for gas compound measurement concerns overall three domains: environmental monitoring, emission measurement and risk assessment. These fields are different because of concentration range (from $10^{-3}$ to thousands $\mathrm{mg}^{-\mathrm{m}^{-3}}$ ). $\mathrm{A} \mathrm{fast}$ technique has been developed based on UV spectrophotometry. Simple robust optics and absence of interference from water vapour and carbon dioxide are two of the main benefits of this method. All measurements are performed with a quartz flow cell of $10 \mathrm{~cm}$ pathlength. In this condition, the detection limits of various compounds (ammonia, hydrogen sulphide, sulphur dioxide, benzene, toluene, ethylbenzene and p-xylene) vary between 30 and $100 \mathrm{mg} . \mathrm{m}^{-3}$. This UV spectrometry system has been tested with success in two applications. The first one is during gaseous ammonia dispersion, simulating a chemical accident. The second one is BTEX monitoring measurement in a process control of soil remediation. In this case, UV is associated with spectral data treatment software. All results are compared with reference methods (Nessler reagent for ammonia, gas chromatography for BTEX). An acceptable agreement was found.
\end{abstract}

Keywords. UV spectrophotometry - gaseous phase - toxic gas - analysis.

\section{Introduction}

There are many instances where it is necessary or desirable to determine concentration of gas alone or in mixture. For example, to face chemical hazards, firemen need reliable and portable tools in order to determine implicated species. Moreover gaseous pollutant analysis is necessary in the environment to monitor air quality [1] or in industrial use such as chemical process control or occupational health [2]. The concentration range (from $10^{-3}$ to thousands $\mathrm{mg} . \mathrm{m}^{-3}$ ) differs with these domains, environmental monitoring, emission measurement and risk assessment.

Many different analytical techniques can be used to detect pollutants in gaseous phase. Optical systems [3,4] with a long pathlength, including Fourrier Transform Infra Red (FTIR), diode laser spectroscopy and Differential Optical Absorption Spectroscopy (DOAS), have been developed to detect lower concentrations (ppbv to around 100 ppmv). For concentrations ranging from 0 to around 5000 ppmv, chemical methods [2-7] such as colorimetry or electrochemical sensors are usual systems. Recently, infrared techniques [8] are also being used to analyse carbon dioxide, hydrogen chloride, ammonia, nitrogen oxide, sulfur dioxide... For this last compound, UV chemiluminescence [9] is the industry accepted standard. In general these techniques are used to analyse inorganic compounds. The most common measurement technique used for the detection of aromatic species so far is the combination of gas chromatography (GC) with either a flame ionisation detector (FID) or mass spectroscopy [10].

Another method, based on classical UV spectrophotometry, has been developed for gas determination. Two of the main benefits of UV spectrophotometry for analysing gaseous compounds are the ease and robustness of optical technique and the absence of interference from water vapour and carbon dioxide [11].

Thus, this work presents UV spectral examination by direct absorptiometry and multiwavelength approach. Absorptiometry has been used to analyse inorganic and organic gas compounds, $\mathrm{NH}_{3}, \mathrm{H}_{2} \mathrm{~S}, \mathrm{SO}_{2}$, benzene, toluene, ethylbenzene and xylene, in order to determine detection limits, effective range and accuracy of UV analysis. This method is inappropriate to multigas analysis due to the superposition of some spectra broadbands. However, this research permitted us to constitute a spectral database necessary to the study of gas mixtures. An automatic resolution method for deconvolution of the signal is thus required to identify and quantify compound mixture [12,13]. A deconvolution procedure has been tested on a mixture of benzene, toluene, ethylbenzene and para-xylene (this mixture will be called BTEX). Each of these methods is validated by an application. The first one is a technological accident with ammonia. The second one is an on line BTEX control of a soil remediation process.

\section{Materials and methods}

\section{Reagents}

Inorganic compounds: Ammonia, hydrogen sulphide and sulphur dioxide are from Air Liquide, France. Purity is higher than $99 \%$.

*Correspondence and reprints.

Received August 9, 2000; revised December 14; accepted December 18, 2000. 
Organic compounds: Benzene, ethylbenzene, toluene and pxylene (BTEX) were obtained from Carlo Erba and were used as received (purity higher than 99,5\%).

\section{Gas generation system}

Two systems are developed according to physical characteristics of the studied compounds in the standard conditions of temperature and pressure $\left(20{ }^{\circ} \mathrm{C}, 1\right.$ bar $)$. These systems are shown on figure 1.

Inorganic compounds: $\mathrm{NH}_{3}, \mathrm{H}_{2} \mathrm{~S}$ and $\mathrm{SO}_{2}$ are gases in standard conditions of temperature and pressure $\left(20{ }^{\circ} \mathrm{C}\right.$, 1 bar). In this case an electronic flow meter adapted to gases is used (Brooks 5800). The gas, with a known flow-rate, is diluted in an air stream (Fig. 1). The gas concentration can be modified by changing flow-rates of the studied gas or air. All measurements are performed at standard conditions, around $20{ }^{\circ} \mathrm{C}$ and $1 \mathrm{bar}$, because concentrations are temperature and pressure dependent. The precision of this system is around $5 \%$.

Organic compounds: Benzene, toluene, ethylbenzene and xylene are liquids in standard conditions of temperature and pressure $\left(20{ }^{\circ} \mathrm{C}, 1 \mathrm{bar}\right)$. Liquids are volatilised with an infusion pump (Precidor type 5003) and diluted by air (see Fig. 1). Concentration is varied by variation of infusion pump speed or air flow-rate. The precision of this system is about $10 \%$.

\section{Optic system}

All measurements have been performed by using a SECOMAM spectrometer model S1000 with a resolution of $1 \mathrm{~nm}$. The flow cell is $10 \mathrm{~cm}$ long and optical faces are Suprasil Quartz. UV spectra are recorded between 200 and $350 \mathrm{~nm}$. The spectrometer is coupled with data processing software (UVRES, SECOMAM) for a multicomponent approach.

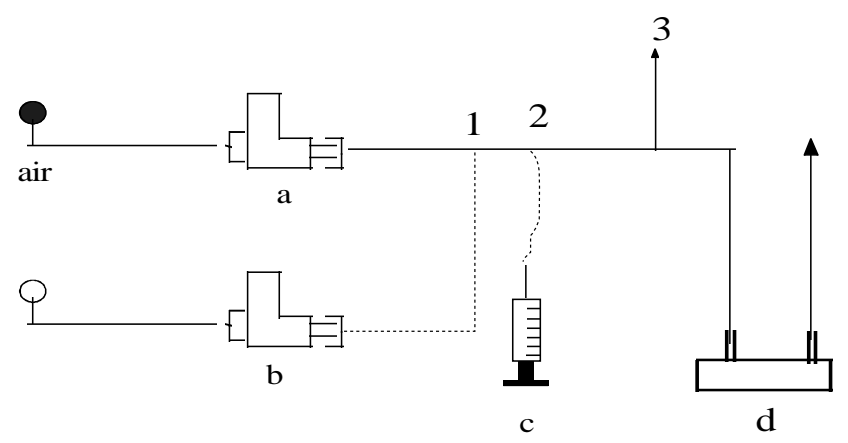

Figure 1. Flue gas generation. a. air flow-rate controller; b. gas flow-rate controller; c. infusion pump; d. UV optical cell $10 \mathrm{~cm}$ long. 1. inorganic compound generation; 2. organic compound generation; 3. analytical methods (colorimetry for $\mathrm{NH}_{3}$ and $\mathrm{H}_{2} \mathrm{~S}$, iodometry for $\mathrm{SO}_{2}$ and gas chromatography for BTEX).

\section{UV spectropthotometry procedures}

These methods are based on Beer Lambert law, which establishes a proportionality between the compound concentration and the measured absorbance.

\section{Absorptiometry or monowavelength analysis}

This method uses a single wavelength. Knowing the absorbance with a defined concentration, it is easy to determine an unknown concentration of this same species at a given wavelength. The selection of the wavelength must be carried out. This choice is simple if the studied compound has a characteristic broadband absorption. It becomes less obvious when the spectrum is unstructured. After having selected the suitable wavelength the gas analysis is performed. For each compound and concentration, ten spectra are acquired. Then the repeatability is tested with the following relationship,

$$
r=\frac{2 \sigma}{\mathrm{C}_{\text {true }}} \times 100
$$

where $\sigma$ is the standard deviation of the ten spectra acquired. The calibration, $A_{\lambda_{\mathrm{i}}}=f\left(c_{j}\right)$, is calculated on the average of these spectra. The slope corresponds to the molar extinction coefficient, according to the Beer-Lambert law. The linearity range of this law determines the effective range of compound concentrations. In order to determine the detection limits, twenty air spectra, considered as a baseline, are carried out, from which the standard deviation, $\sigma$, is calculated. The detection limit is equivalent to $3 \sigma$.

\section{Multiwavelengths procedure}

For determining the total concentration of the mixture and contributions of each species, a statistical processing is carried out. The principle is based on spectral deconvolution, classical multicomponent analysis by using a deterministic approach. Any spectrum can be considered as a weighted sum of spectra of absorbing species in the linearity range of the Beer-Lambert law. A classical least squares algorithm is used for the calculation of spectral contributions with the study of the associated quadratic error (value and distribution). It is summarised by the following matrix expression (1) $[12,13]$ :

$$
S U=\sum_{i} a_{i} S R_{i}+E
$$

$S U$ : spectrum of the mixture restituted

$S R_{i}$ : reference spectra corresponding to each compound $a_{i}$ : contribution coefficient of each reference spectrum $E$ : minimised error calculated as equation (2):

$$
E=\sum_{i}\left[A_{\text {mesured }}\left(\lambda_{i}\right)-A_{\text {restored }}\left(\lambda_{i}\right)\right]^{2} .
$$

In practice, it can be assumed that the UV spectrum of an unknown sample can be obtained by using a linear 


\section{Original articles}

combination of a small number of defined reference spectra, related to specific compounds. This method has been designed for wastewater characterisation $[14,15]$. Then it is applied in air to detect and quantify gas mixtures. In the deconvolution approach, reference spectra of compounds interest can be selected if corresponding concentrations are included in the linearity range of the Beer-Lambert law. Moreover, these spectra must be independent from a mathematical point of view.

\section{Analytical methods}

All UV measurements have been compared with an analytical method.

$\mathrm{NH}_{3}, \mathrm{H}_{2} \mathrm{~S}$ and $\mathrm{SO}_{2}$ are respectively trapped and analysed by using the following methods: $\mathrm{NH}_{3}$ by colorimetry with Nessler's reagent from $\mathrm{HCl}$ solution [16], $\mathrm{H}_{2} \mathrm{~S}$ by colorimetry with Methylene Blue from $\mathrm{NaOH}$ solution [17], $\mathrm{SO}_{2}$ by iodometry from iodine solution [18]. In all cases, the gas $\left(\mathrm{NH}_{3}, \mathrm{H}_{2} \mathrm{~S}\right.$ or $\left.\mathrm{SO}_{2}\right)$ is bubbled during five minutes in to $200 \mathrm{ml}$ of the appropriate solution at $0.1 \mathrm{M}$.

BTEX are analysed by gas chromatography. The gas chromatograph is a Varian 3400 coupled with a flame ionisation detector. A 25 metres HP-5 capillary column is used with a carrier gas (nitrogen) flow-rate of $3.2 \mathrm{ml} . \mathrm{min}^{-1}$. Separation is conducted in less than twenty minutes.

\section{Absorptiometry results and discussions}

In the first step, the selection of a working wavelength has been performed for each analysed species. In the second step the calibration of the method has been investigated and validated by on an application to ammonia.

\section{Wavelengths choice}

Two forms of spectra appear. The first is an unstructured spectrum such as of $\mathrm{H}_{2} \mathrm{~S}$ (Fig. 2a). In this case, the second derivative is calculated to achieve a characteristic wavelength (shoulder, inflection point). The second is characterised by a broadband such as of xylene (Fig. 2b).

$\mathrm{NH}_{3}$ : the spectrum is unstructured. It shows a monotonous decrease between 200 and $220 \mathrm{~nm}$. Shoulders have been observed at 205, 208, 212 and $216 \mathrm{~nm}$, corresponding to rotational and vibrational transitions [19]. At the wavelength of $205 \mathrm{~nm}$, the absorbance is stable and sensitivity is correct.

$\mathrm{H}_{2} \mathrm{~S}$ : this spectrum is similar to the spectrum displayed by $\mathrm{NH}_{3}$ in the range from 200 to $300 \mathrm{~nm}$. The inflection point is at $203 \mathrm{~nm}$, the chosen wavelength.

$\mathrm{SO}_{2}$ : this spectrum is characterised by a broadband where the absorbance maximum is located at $285 \mathrm{~nm}$

BTEX: Two peaks have been observed, one near $200 \mathrm{~nm}$ and the other near $260 \mathrm{~nm}$. Indeed, benzene presents electronic transitions $\Pi \rightarrow \Pi^{*}$ around $200 \mathrm{~nm}$ and $250 \mathrm{~nm}$.
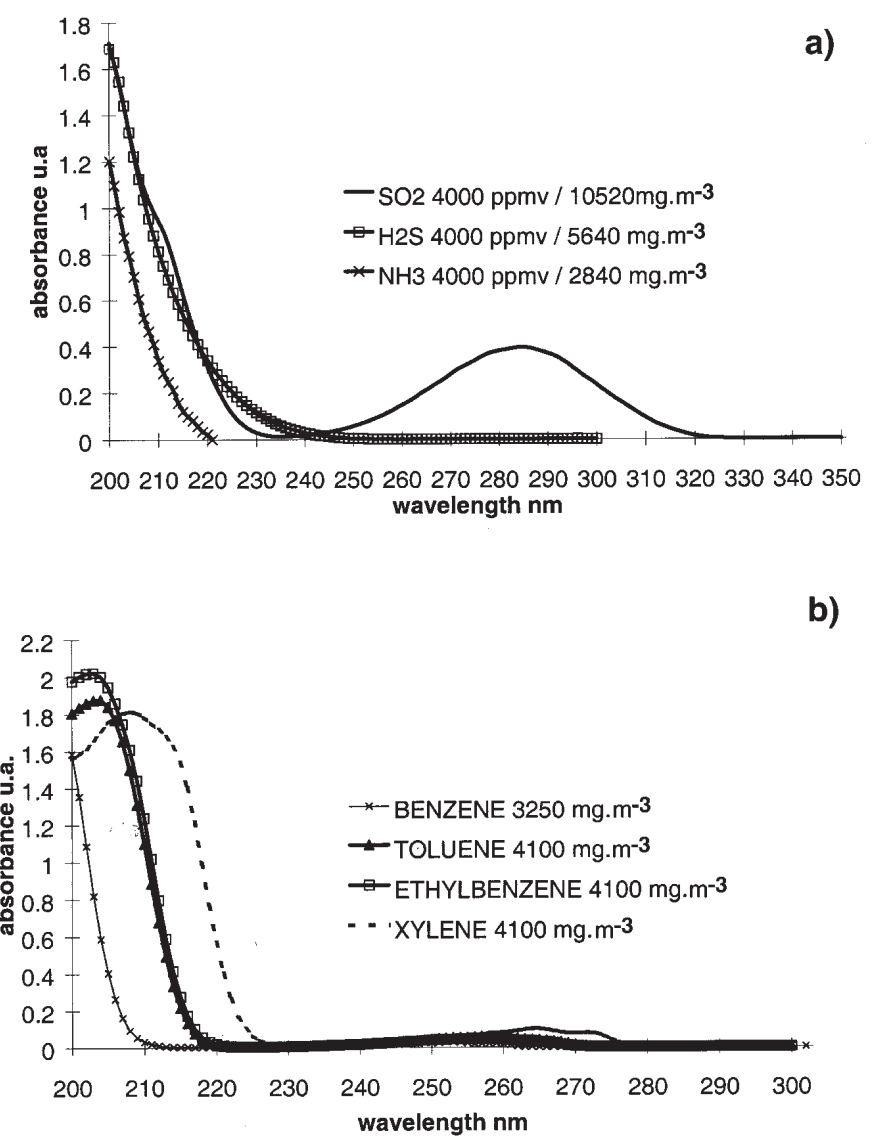

b)

Figure 2. Compound spectra. (a) inorganic compound, (b) organic compound.

Hydrogen substitution by a alkyl group produces a bathochromic effect at $200 \mathrm{~nm}$ [20]. Wavelengths of maximum absorption are 200, 203, $208 \mathrm{~nm}$ respectively for benzene, ethylbenzene or toluene and xylene. It is noticeable that the toluene spectrum is close to that of ethylbenzene.

These selected wavelength are used to calibrate the absorptiometry procedure.

\section{Calibration of the method}

The performances achieved by the absorptiometry analysis, including calibration, linear dynamic range and accuracy are illustrated on table I.

Inorganic compounds: the effective range varies from detection limits, of $50,5,10 \mathrm{mg} \cdot \mathrm{m}^{-3}$, to maximum measurement, 3600, 5900 and $10520 \mathrm{mg} \cdot \mathrm{m}^{-3}$ respectively for $\mathrm{NH}_{3}, \mathrm{H}_{2} \mathrm{~S}$ and $\mathrm{SO}_{2}$. In the case of $\mathrm{NH}_{3}$, there is absorbance non-linearity. Nevertheless three dynamic linear ranges can be observed and used to analyse ammonia by UV. Low molar extinction coefficient values indicate the low UV sensitivity of the inorganic products. 
Table I. Absorptiometry results.

\begin{tabular}{lcccc}
\hline Compound & $\begin{array}{c}\text { Effective range } \\
\text { mg.m }^{-3}\end{array}$ & $\begin{array}{c}\varepsilon(\lambda \mathrm{nm}) \\
\text { L.mol }^{-1} . \mathrm{cm}^{-1}\end{array}$ & $\begin{array}{c}R^{2} \\
\%\end{array}$ & $r$ \\
\hline & {$[50 ; 450]$} & $675(205 \mathrm{~nm})$ & 0.995 & \\
$\mathrm{NH}_{3}$ & {$[450 ; 1150]$} & $410(205 \mathrm{~nm})$ & 0.998 & 5 \\
& {$[1150 ; 3600]$} & $255(205 \mathrm{~nm})$ & 0.999 & \\
$\mathrm{H}_{2} \mathrm{~S}$ & {$[5 ; 4900]$} & $865(203 \mathrm{~nm})$ & 0.998 & 4 \\
$\mathrm{SO}_{2}$ & {$[10 ; 10520]$} & $236(285 \mathrm{~nm})$ & 0.999 & 3 \\
$\mathrm{Benzene}_{\text {Toluene }}$ & {$[60 ; 3250]$} & $3945(200 \mathrm{~nm})$ & 0.991 & 5 \\
Ethylbenzene & {$[100 ; 4100]$} & $4304(203 \mathrm{~nm})$ & 0.994 & 5 \\
Xylène & {$[30 ; 4100]$} & $5202(203 \mathrm{~nm})$ & 0.997 & 5 \\
& {$[30 ; 4100]$} & $4829(208 \mathrm{~nm})$ & 0.993 & 5 \\
\hline
\end{tabular}

a: from detection limit to maximum measurement.

Organic compounds: the effective range is restricted mainly by the species volatilisation stopping at $4100 \mathrm{mg} \cdot \mathrm{m}^{-3}$. The detection limits vary between 30 and $100 \mathrm{mg} \cdot \mathrm{m}^{-3}$ according to the compound. Molar extinction coefficients $(\varepsilon)$ fluctuate with the nature and the number of substituents on benzene. Indeed for benzene, toluene to xylene, the increase of the number of substituent (methyl) explains the increase of $\varepsilon$ value. The difference between xylene and ethylbenzene is assigned to the nature of the substituent, methyl and ethyl, respectively.

All measurements of organic or inorganic compounds are stable with a repeatability $(r)$ within $5 \%$, which defines the UV sampling error. Moreover, each correlation coefficient $\left(R^{2}\right)$ is higher than 0.99 .

\section{Application: simulation of chemical ammonia accident}

This simulation of an accident was carried out on an experimental site located in Champclauson (Gard, France). The trials were based on the release of ammonia in the presence and absence of water curtains [21]. Liquefied ammonia was stored under pressure in a steel bottle (B84 from L'Air Liquide) at its vapour saturation pressure (7.7 bars for a temperature of $\left.17{ }^{\circ} \mathrm{C}\right)$. The bottle was inclined with the nozzle facing downwards, in order to produce a release in the horizontal downwind direction, during two minutes with a flowrate of approximately $5 \mathrm{~kg} \cdot \mathrm{min}^{-1}$. Measurement points were distributed on arcs (at 15, 25, 35 and 50 meters from the emission source) in the direction of ammonia release to follow ammonia content during passage of the cloud. The sampling was performed by pumping up the ammonia-air mixture and by capturing it in $200 \mathrm{ml}$ of hydrochloric acid solution $(0,1 \mathrm{M})$. This solution is then dosed by Nessler's reagent. The experimental facilities on the site are illustrated on figure 3 .

Thus to validate the UV absorptiometry procedure, the application consists in positioning UV sampling systems close to those usually used (bubbling in to the hydrochloric acid solution) and to compare concentrations obtained by the two methods. The UV sampling system is composed of a Tedlar bag and a pump. The gas mixture is trapped in the
Table II. Results of simulated accident.

\begin{tabular}{|c|c|c|}
\hline $\begin{array}{cl}{[\mathrm{NH} 3]_{\mathrm{UV}} \mathrm{ppm}_{\mathrm{v}}} \\
\pm \Delta[\mathrm{NH} 3]_{\mathrm{UV}}^{\mathrm{a}} \\
\text { UV }\end{array}$ & $\begin{aligned} & {[\mathrm{NH} 3]_{\mathrm{ca}} \mathrm{ppm}_{\mathrm{v}} } \\
& \pm \Delta[\mathrm{NH} 3]_{\mathrm{ca}} \\
\text { ca: } & \text { chemical analysis }\end{aligned}$ & $\begin{array}{l}\text { Accuracy } \\
\text { E1 } \\
\%\end{array}$ \\
\hline $\begin{array}{c}570 \pm 30 \\
390 \pm 20 \\
470 \pm 25 \\
580 \pm 30 \\
1450 \pm 70 \\
345 \pm 15 \\
160 \pm 10 \\
5140 \pm 260 \\
1825 \pm 90 \\
890 \pm 45\end{array}$ & $\begin{array}{c}670 \pm 100 \\
400 \pm 60 \\
450 \pm 70 \\
710 \pm 110 \\
1470 \pm 220 \\
320 \pm 50 \\
150 \pm 25 \\
4980 \pm 750 \\
1700 \pm 255 \\
760 \pm 115\end{array}$ & $\begin{array}{c}-15 \\
-2 \\
+5 \\
-18 \\
-1.4 \\
-8 \\
+7 \\
+3.2 \\
+7.3 \\
+17\end{array}$ \\
\hline \multicolumn{3}{|c|}{ a: UV sampling error: $\frac{\Delta\left[\mathrm{NH}_{3}\right]_{\mathrm{UV}}}{\left[\mathrm{NH}_{3}\right]}=5 \%$} \\
\hline \multicolumn{3}{|c|}{ b: chemical sampling error: $\frac{\Delta\left[\mathrm{NH}_{3}\right]_{\mathrm{ca}}}{\left[\mathrm{NH}_{3}\right]_{\mathrm{ca}}}=15 \%$} \\
\hline $\mathrm{c}: \mathrm{E} 1=\frac{\left[\mathrm{NH}_{3}\right]_{\mathrm{UV}}-\left[\mathrm{NH}_{3}\right]_{\mathrm{c}}}{\left[\mathrm{NH}_{3}\right]_{\mathrm{ca}}}$ & 100 & \\
\hline
\end{tabular}

bag by using a pump, during the time of the test. The trapped gas is analysed by absorptiometry at $205 \mathrm{~nm}$, the selected wavelength to analyse ammonia with the calibration achieved above (Tab. I).

The UV sampling system has been tested in the laboratory. Accuracy has been estimated at $5 \%$.

The results obtained by calibration are listed in table II. Considering the higher sampling error of chemical analysis, around $15 \%$, the two methods are in good agreement. Indeed, the accuracy E1 never exceeds $20 \%$ corresponding to the sum of UV sampling error and chemical sampling error. However the spectrometric technique is more accurate (sampling error is of $5 \%$ ) than the chemical technique. Compared to this analysis, the proposed method requires no sample preparation and no reagent, which allows rapid analysis.

\section{Absorptiometry conclusion}

Although the results by the absorptiometry method seem to be very good, there are some limitations to this procedure. The main limitation relates to single pure species analysis because of possible interference by another gas.

\section{Multiwavelength procedure results and discussions}

The multiwavelength procedure is necessary to analyse mixtures due to the absorbance additivity law. Indeed, 


\section{Original articles}

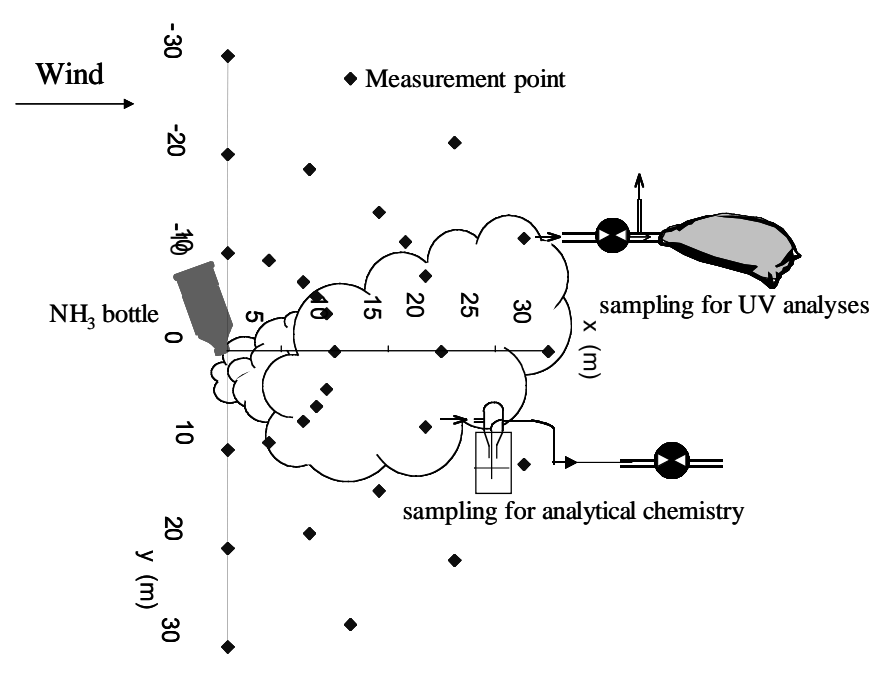

Figure 3. Measurement points for an ammonia accident.

absorbance of mixture at a given wavelength is equal to the sum of individual species absorbance at the same wavelength.

Before analysing gas mixtures, the selection of reference spectra and the study of their independence were carried out.

\section{Reference spectra}

For quantitative application by the procedure described above, it is necessary to define one or several spectra and the spectral exploitation range.

The linearity of the Beer-Lambert law is maintained from 0 to $4000 \mathrm{mg} \cdot \mathrm{m}^{-3}$. Reference spectra must be chosen among those corresponding to the previous concentration range. Reference spectra are established from an average of 5 spectra at $1070 \mathrm{mg} \cdot \mathrm{m}^{-3}$ for benzene, $1200 \mathrm{mg} \cdot \mathrm{m}^{-3}$ for toluene, $1060 \mathrm{mg} \cdot \mathrm{m}^{-3}$ for ethylbenzene and $960 \mathrm{mg} \cdot \mathrm{m}^{-3}$ for xylene. A background correction is added to minimise deviations due to noise. The spectral range is between 200 and $300 \mathrm{~nm}$.

\section{Verification of reference spectra independence}

This study aims to examine if the spectra of benzene, toluene, ethylbenzene and xylene interfere between them. Spectra of each species alone in air, with several known concentrations are treated by spectral deconvolution. Thus, contribution coefficient values are compared with the true values. The method correctly produces the spectra of xylene and benzene. However, the deconvolution procedure interprets the ethylbenzene spectrum as a mixture of toluene and ethylbenzene. Indeed, in the ethylbenzene spectrum where concentrations exceed $1060 \mathrm{mg} \cdot \mathrm{m}^{-3}$, toluene appears, refer to figure $4 \mathrm{a}$. On the other hand, the multiwavelength approach interprets correctly toluene spectra for concentrations lower than $1600 \mathrm{mg} \cdot \mathrm{m}^{-3}$. For a toluene concentration

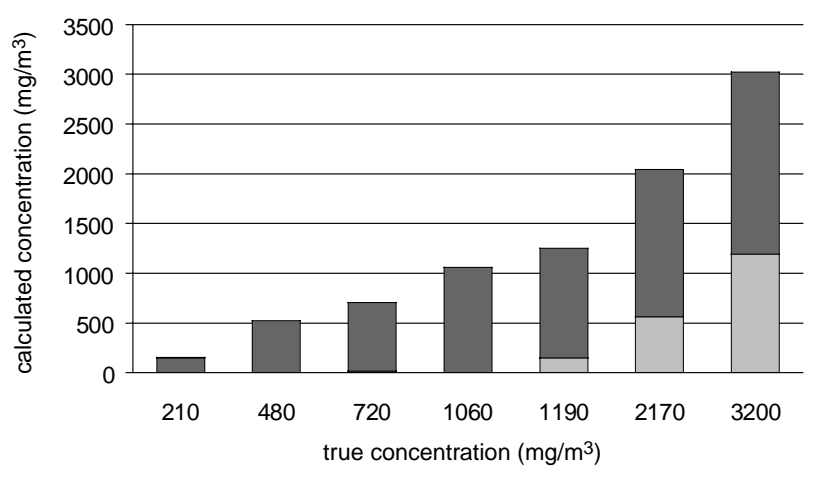

ロBENZENE $\square$ TOLUENE $\square$ ETHYLBENZENE $\square$ XYLENE

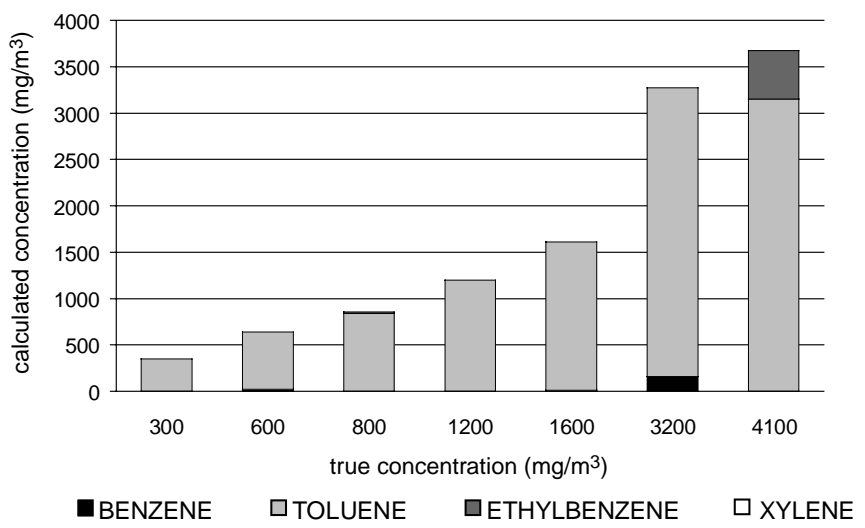

Figure 4. UVRES results of ethylbenzene (a) and toluene (b).

equal to $3200 \mathrm{mg} \cdot \mathrm{m}^{-3}$, the method indicates a mixture of toluene and a low concentration of benzene $\left(120 \mathrm{mg} \cdot \mathrm{m}^{-3}\right)$. The hypothesis for explaining this phenomenon is that the error of restitution is minimised by adding another compound (see equation 1 and equation 2). For a toluene concentration equal to $4100 \mathrm{mg} . \mathrm{m}^{-3}$, the method indicates a mixture of toluene and ethylbenzene (about $500 \mathrm{mg} \cdot \mathrm{m}^{-3}$ ). This phenomenon can be explained owing to spectral similarities of toluene and ethylbenzene.

\section{Application to a BTEX mixture}

Mixtures of BTEX with known concentrations in the gas phase are analysed simultaneously by spectrometry UV and gas chromatography (Fig. 1).

Calculated concentrations for mixtures of benzene, toluene, ethylbenzene and xylene (Tab. IIIa) show that it is possible to measure in the gaseous phase the concentrations of each compound in a mixture of benzene, toluene, ethylbenzene and xylene. Accuracy E2, table IIIa, does not exceed $10 \%$, corresponding to the sum of UV sampling error and GC sampling error. This accuracy is acceptable in the case of chemical process control. 
Table III. Results of BTEX mixture. a) benzene, toluene, ethylbenzene and xylene mixture, b) toluene and ethylbenzene mixture.

\begin{tabular}{|c|c|c|c|c|}
\hline Compound & $\begin{array}{l}\text { Cgenerated } \\
\text { mg. } \mathrm{m}^{-3}\end{array}$ & $\begin{array}{c}\text { Cspectrometry } \\
m g . m^{-3}\end{array}$ & $\begin{array}{c}\text { Cchromatography } \\
m g . m^{-3}\end{array}$ & $\begin{array}{c}\text { Accuracy } \\
\text { E2 }{ }^{a} \%\end{array}$ \\
\hline \multicolumn{5}{|l|}{ a) } \\
\hline Benzene & 430 & 510 & 465 & 10 \\
\hline Toluene & 215 & 260 & 240 & 8 \\
\hline Ethylbenzene & 215 & 270 & 255 & 6 \\
\hline Xylene & 215 & 240 & 240 & 0 \\
\hline Sum & 1075 & 1280 & 1195 & 7 \\
\hline \multicolumn{5}{|l|}{ b) } \\
\hline toluene & 750 & 1100 & 800 & 37.5 \\
\hline ethylbenzene & 320 & 0 & 300 & 100 \\
\hline Sum & 1070 & 1100 & 1100 & 0 \\
\hline
\end{tabular}

a: $\quad \mathrm{E} 2=\frac{\mathrm{C}_{\text {spectrometry }}-\mathrm{C}_{\text {chromatography }}}{\mathrm{C}_{\text {chromatography }}} \times 100$

A problem appears with toluene and ethylbenzene (Tab. IIIb). If one of these two compounds has a higher concentration, the result given by this method corresponds to the sum of the compounds with the weakest concentration is regarded as a background noise due to similar UV spectra. Then toluene and ethylbenzene cannot be distinguished.

\section{Control on line of soil remediation process}

Venting is an in situ system of soil decontamination by extraction of the air containing the volatilised pollutant [22]. The research is to test the efficiency of applicability of pulsed venting in soil remediation [23]. Extract pollutants are analysed by gas chromatography directly in the field. Then UV spectrophotometry coupled with the multiwavelength procedure is tested to control pulsed vapour extraction in order to develop this method as an alternative technique of procedure monitoring.

The pilot study in the laboratory is represented by a column filled with sand, polluted by BTEX, refer to figure 5 . The spectrometer is between the column and the pump. Thus spectra are measured on line. Chromatography sampling is carried out downstream of the column.

An example of concentration control is presented on figure 6. Analysis of these curves shows that spectrometry over-estimates benzene and toluene concentrations by approximately $30 \%$. In the case of ethylbenzene and xylene, the relative error between the concentrations found by the two methods is lower than $10 \%$ (Fig. 6a). Total concentrations measured by UV spectrometry are also higher by approximately $30 \%$ than those obtained by chromatography (Fig. 6b). This over-estimate is due to a compound formed by reaction between BTEX and column. A peak appears on the chromatogram, which was not taken into account in the quantitative analysis. This product absorbing in the UV region, was quantified by spectrometric analysis. However, a similar of UV and GC results have been observed

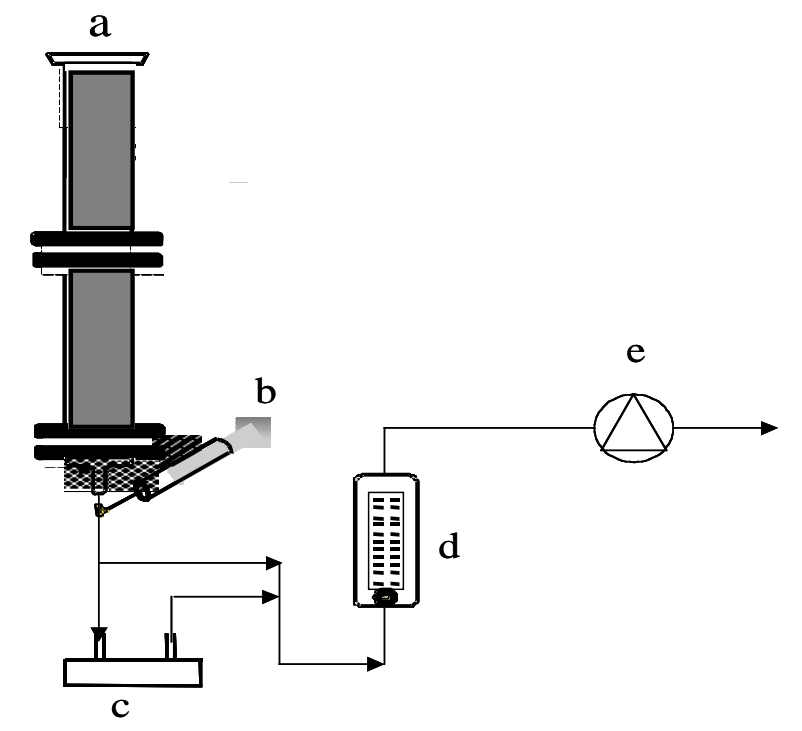

Figure 5. Scheme of pilot test representing an soil remediation process. a. column filled with sand and polluted with BTEX; b. GC sampling, c. UV optic cell $10 \mathrm{~cm}$ long; d. flow-rate 10 L.min ${ }^{-1}$; e. pump aspiring polluted air.

(Fig. 6b). UV spectrophotometry gives more homogeneous results because this method requires no sampling and transport. Thus UV spectrophotometry is as an interesting remediation monitoring method for contaminants of the BTEX.

\section{Multiwavelength procedure conclusion}

The multiwavelength method provides direct and simultaneous measurement of total BTEX concentration and contribution of each component. In spite of similar spectra of 


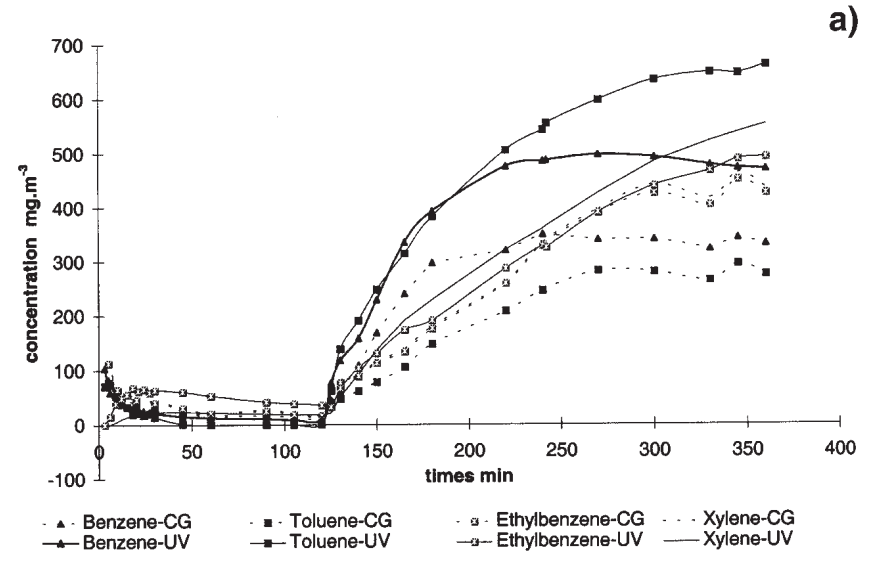

b)

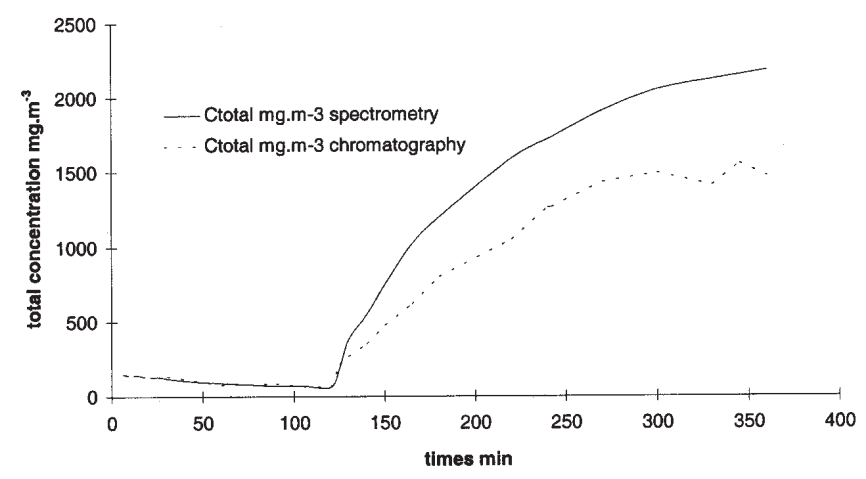

Figure 6. (a) measurement on line of separated compound, benzene, toluene, ethylbenzene and xylene, (b) measurement on line of concentration sum of BTEX.

toluene and ethylbenzene, the multiwavelength procedure must be considered as an aggregate system, which can analyse some compounds in a mixture.

\section{Conclusion}

In the search for a simple tool for the identification and quantification of toxic gases, the use of UV spectrometry appears promising. If there is a single gas, absorptiometry is sufficient and if it is desirable to determine concentrations of individual analytes in a mixture of gas or to know total concentration of the mixture, UV spectrophotometry coupled with a multiwavelength procedure is necessary.

Indeed the first method, absorptiometry, carried out on usual gaseous components, $\mathrm{NH}_{3}, \mathrm{SO}_{2}, \mathrm{H}_{2} \mathrm{~S}$ and usual organic compounds, benzene, toluene, ethylbenzene, xylene, showed that measurement of various gas concentrations was possible. This system is attractive because of its efficiency, rapidity and simplicity. Moreover values for detection limits comprise between 5 to $100 \mathrm{mg} \cdot \mathrm{m}^{-3}$, close to values authorised by French legislation. The main limitations of absorptiometry relate to single pure species analysis and possible interference with another gas due to the absorbance additivity law.

The spectral deconvolution by data processing in addition makes it possible to analyse mixtures. Indeed the multiwavelength method provides direct and simultaneous measurement of total BTEX concentration and contribution of each compound. In spite of similar spectra of toluene and ethylbenzene, the multiwavelength procedure must be considered as an aggregate system, which can analyse some compounds in a mixture. Application to process control of soil remediation has shown that UV spectrophotometry is an interesting remediation monitoring method for contaminants of type BTEX.

\section{Reference}

1. Clement, R.E.; Yang, P.W. Anal. Chem. 1999, 71, 257R-292R.

2. Accorsi, A. Spectra 2000 1987, 15, n 121, 34-42.

3. Grant W., Kagann, R.; McClenny, W. Journal of the Air and Waste Management Association 1992, 42, $\mathrm{n}^{\circ} 1,18-30$.

4. Kolb, C.E.; Wormhoudt, J.C.; EDS Matson, P.A; et al. 1995, pp 259-290.

5. Poulleau, J. Pollution atmosphérique 1996, Oct.-Dec., 50-58.

6. Stupay, P. Semiconductor international 1997, 20, 6, 239-248.

7. Janata, J.; Josowicz, M. Anal. Chem. 1998, 70, 179R-208R.

8. Belhamza, A.; Kalb, G.; Sabrié, C. Pollution atmosphérique 1998, June, 58-64.

9. Harris, P. ISATECH97 Conf. Oct 1997 Anaheim 1994, 1, 221232.

10. Trost, B.; Stutz, J.; Platt, U. Atmospheric Environment 1997, 31, 23, 3999-4008.

11. Harris, P.; Hamish, A. Advances in Instrumentation and Control 1996, 29, 321-332

12. Gallot, S.; Thomas, O. International journal of environment analytical 1993, 52, 149-158.

13. Thomas, O.; Theraulaz, F.; Agnel, C.; Suryani, S. Environmental technology 1996, 17, 251-261

14. Touraud, E.; Crone, M.; Thomas, O. Field Analytical chemistry and technology 1998, 2, 4, 221-229

15. Vaillant, S.; Pouet, M.F.; Thomas, O. Talanta 1999, 50, 729736.

16. Norme française homologuée, AFNOR, 1975, T 90-015.

17. Charlot G.; Dosages colorimétriques des éléments minéraux; Paris: Masson, $2^{\text {nd }}$ edition, 1961, pp 328-329

18 Charlot G. Dosages colorimétriques des éléments minéraux; Paris: Masson, $2^{\text {nd }}$ edition, 1961, pp 329-330.

19. Yoshikazu, N.; Toshio, T.; Takahiro, K. Analytical Sciences 1997, 13, n³, 379-383.

20. Sylverstein, R.; Bassler, G.C.; Morril, T.C. Spectrometric Identification of organic compounds; New York: Wiley, 4th edition, 1981, $441 \mathrm{p}$.

21. Bara, A. Ph. D. Thesis, Université Aix-Marseille I, France, May 2000.

22. Roudier, Descriptif des techniques de dépollution : Réhabilitation des sols des Nappes Phréatiques, ATE, 1995.

23. Kvapil, P. Ph. D. Thesis, Université Aix-Marseille I, France, January 2000. 